\title{
Can measuring the benefits of accessible transport enable a seamless journey?
}

\author{
Alice Maynard \\ Future Inclusion, Ltd. ${ }^{a}$
}

\begin{abstract}
For disabled and older people, journeys need to be seamless - with no failures in access from origin to destination. Because the public transport environment, including walking and cycling modes, is not accessible, the use of private cars remains essential to social inclusion. Consequently, social goals relating to private car use in relation to health, environment and land-use will be harder to achieve. Greater attention needs to be paid to the detail of the "journey chain" with access consistently provided throughout, making for seamless journeys. This attention needs to be paid in all aspects of transport planning as well as delivery, including in the appraisal process. In transport projects appraisal, the costs of providing access are monetized, but not the benefits. The author undertook an experiment to value the benefits of step-free access for everyone and found significant economic benefit that enhanced the benefit:cost ratio. Until the benefits of accessible transport are properly considered for everybody across the whole planning process including appraisal, providing access will continue to be an uphill struggle and access throughout the journey chain will remain hit and miss.
\end{abstract}

Keywords: Economic appraisal, Transport, Accessibility, Social model of disability

\section{Introduction}

There is a general consensus in society that getting people out of their cars and onto public transport, or their own feet or wheels, is ever more necessary to improve public health, protect the environment and relieve congestion.

One might reasonably assume that the complementary goals of reducing environmental impacts, improving health, and improving land-use efficiency are also intended to get disabled and older people out of their cars. However, there is a well-rehearsed argument that disabled and older people are less able-or, in some cases, unable-to use public transport (including walking and cycling), and therefore that use of the private car (with the concomitant concessions such as "blue badge" parking and exemptions from congestion charging) is considered vital to disabled and older people's social inclusion. For everyone, the shift to public transport use requires a seamless and easily negotiated interface between the origin, the public transport network, and the destination. For disabled and older people, the details of the interface are crucial, and that level of detail is not always considered in mainstream transport planning.

This paper explores, in the context of the United Kingdom, how the design of environments that exclude disabled and older people perpetuates their need to use private cars and militates against other social goals. Referring to a study that derived willingness-to-pay values

ªrearch@futureinclusion.com 
for specific aspects of access for disabled people, it asks whether a more detailed understanding of the economic benefits of disabled and older people's inclusion in relation to the whole journey would improve the provision of public transport, get more disabled and older people out of their cars, and thereby contribute to the realization of health, environmental, and land-use benefits.

\section{The traditional exclusion of disabled people}

\subsection{Models of disability}

Disabled people have for over two decades advocated the use of the "social model of disability" (Barnes 1991). This model holds that it is barriers to access in the physical, sensory, and social environment that cause disability, where disability is defined as the lack of opportunity to participate in mainstream activities. This is in contrast to the "individual model of disability," which holds that there is a causal link between impairment and disability-that is, someone who has an impairment such as a mobility or visual impairment is necessarily disabled and thus unable to participate in mainstream activities. The social model holds that people with impairments are disabled when society fails to take account of their needs, so disability is contingent upon an inaccessible environment, not an impairment. For example, under the social model of disability, the inability of a wheelchair user to participate in an activity does not result from their use of a wheelchair, but from the activity being held on an upper floor of a building without a lift. Similarly, the inability of someone with a visual impairment to participate in discussions at a meeting does not result from their visual impairment, but from the briefing paper being tabled, rather than being provided in a timely fashion (i.e., before the meeting) in an accessible format.

\subsection{Barriers in the physical environment}

The ways in which the built environment and transport infrastructure are organized create numerous barriers for disabled people with a wide range of impairments. Poor layout of buildings and streets presents barriers to people with learning difficulties who need straightforward environments to navigate. Inadequate color contrast in waiting shelters at bus stops and rail stations presents barriers to many people with visual impairments.

Litman (2007, p. 7) identifies four different "geographic scales" of accessibility (in the transport sense; see "Language," below):

"At a fine-grained scale, accessibility is affected by the quality of the pedestrian conditions and the clustering of activities within a site, mall or commercial center. At the neighborhood level, accessibility is affected by the quality of sidewalks and cycling facilities, street connectivity, geographic density and mix. At the regional level, accessibility is affected by street connectivity, transit service, geographic density and mix. Inter-regional accessibility refers to the quality of highways, air service, bus and train service, and shipping services to other regions."

The fine-grained level and the neighborhood level are both important to the ability of disabled and older people to access transport systems. When transport infrastructure is designed, 
the land boundaries generally form the design boundaries. The devil is in the detail of the pavements and paths, the buildings and bollards, but such details in the environment surrounding the transport systems are often not considered when developing or upgrading those systems. Responsibility for the surrounding environment does not generally lie with those developing the transport system. Where it does (for instance, in a local government body), issues related to the surrounding environment and issues related to the transport system itself are often handled by different internal departments or divisions, so boundaries can still exist—through a lack of integrated thinking - preventing a clear view of the whole journey, and consequently disabling people with impairments unnecessarily.

\subsection{Barriers in the social environment}

Barriers in the social environment include organizational barriers: those aspects of organizational culture, systems and processes that prevent access by disabled people. For example, the UK national rail network requires disabled and older people who need assistance at rail stations to book 24 hours ahead; assistance cannot be "guaranteed" unless this is done. This makes it very difficult for disabled people to engage in any activity that requires a train journey on short notice. Furthermore, the way in which the assistance system works means that information concerning a disabled person on a particular train may not always get through to the right people, so assistance may not be available even when it has been booked in advance. A "mystery shopper" survey by Passenger Focus, the UK independent rail watchdog, found that in almost one in five cases assistance for changing trains was not available when required (Passenger Focus 2007).

\subsection{Some underlying causes and results of exclusion}

A major factor in the exclusion of disabled people is the view of disabled people as "other" (Shakespeare 1994). Disabled people are viewed (although not necessarily overtly) as objects of fear because they represent that which nondisabled people wish to avoid in their own lives. In a report published by the think-tank Demos about disablism (Miller et al. 2004), attitudes towards disabled people are described as "often irrational" and the report quotes the Employers' Forum on Disability as saying that "[people] will usually express considerable goodwill towards a group they tend to regard as unfortunate victims... They will also tend to display a deep reluctance to accept disabled people on equal terms." (p.62)

Disabled people are seen to be different from nondisabled people in ways that lead to exclusion. Imrie (1996) explored this phenomenon within a geographical framework, and warned against developing "ablist geographies," through practices such as preferring nondisabled bodies over disabled. Kitchin (1998) explored how the exclusion of disabled people and views of them as "other" demonstrate that disability is spatially constructed, noting that "Space is organized and written to perpetuate disablist practices." (p.346)

One of the manifestations of the spatial construction of disability is the acceptability of providing alternative routes-thus, we do not expect disabled people to use the front entrance like everyone else. Sometimes, the alternative route can be quite long and inconvenient. The British Library in London-a relatively new building - has limited access for wheelchair users. Of the accessible entrances, one is reached via a long route from a small entrance in a side street, which is badly signposted; the other is a staff entrance which is often closed. In addition, a 
striking example of the way in which the detail affecting journeys by disabled and older people is not considered in planning can be found in changes to parking restrictions along one of the nearby roads near the staff entrance, which is the shorter of the two accessible routes to the front door. This can cause disabled and older people for whom distance is an issue (e.g. users of manual wheelchairs and people with walking difficulties) considerable difficulty in visiting the library. The changes demonstrate the lack of consideration given to the whole journey, having been brought about by the local London Borough, not the British Library itself.

Views about the acceptability of providing alternative entrances and exits for disabled people leak into the transport environment. Often, access to a rail station for disabled people is via a) side gate (which may be locked) onto a platform. For many years, the definition of an "accessible" station (i.e. one accessible to people who cannot use stairs) was that it should have step-free access to every platform from the street. In practice, this sometimes meant long and difficult trips from one platform to another via a route that might include car parks and unpaved or unmaintained roads. This was the type of access provided at Thetford Station in Norfolk, where the local train operator was taken to Court under the UK Disability Discrimination Act 1995 due to the difficulty experienced by disabled passengers in changing platforms; the station operator lost the case (Disability Rights Commission 2004). At Kings Cross station in London, the distance to the bus stops for buses traveling South—including those that have replaced the "special" Stationlink bus that shuttled between the major London stations before universal bus accessibility_is much too far for someone with a walking difficulty who might wish to take a bus from Kings Cross Station to, say, Victoria Station.

Where barriers in the environment prevent disabled and older people from using the transport system such that their travel horizons contract and they are not seen "out and about," it appears that there are fewer disabled and older people needing to travel. Arguments can then be made that their needs are better addressed by specialist transport services. A stated-preference experiment undertaken as recently as 2006 asked questions about attitudes toward disabled people and found that more than one-quarter of all participants believed that it would be better to provide specialist transport than to make public transport more accessible (Maynard, 2007a).

Many disabled and older people have had negative experiences of using public transport. There is a fear of failure (DPTAC 2002). In consequence, the provision of accessible transportation has to be reliable - and even where it is, there will be a lag between that provision and pick up. The memory of a dreadful journey often stays with someone for many years-disabled people in the UK will still relate tales of traveling in the Guard's van (a carriage not provided with seats or other fittings in which parcels, bicycles and other large items of luggage could be carried, next to which the guard travelled) on the national rail networks, and when probed, will reveal that their experience dates back 20 years or more. Some disabled people's experiences of ramps on London buses not working has made them reluctant to try again, even though the rate of failure has dropped over the last few years owing to stringent contractual requirements placed on bus companies by Transport for London (Transport for London 2006). Shifting nondisabled people out of their vehicles has proved challenging; shifting disabled and older people out of their cars will require consistency of access throughout the journey chain in order to ensure a seamless journey. Even when consistency has been ensured, patience will still be needed to reap the benefits, as will a clearly targeted communication campaign to ensure that disabled and older people realize they have the opportunity to travel other than by car. 


\section{The Devil is in the detail}

\subsection{The "journey chain"}

When a disabled person makes a journey, every aspect of that journey needs to be accessible. If even a small part of the journey is not, the whole "journey chain" is broken. Encountering a pavement lacking a dropped kerb is, for a wheelchair user, much like a nondisabled person encountering an impassable brick wall along their route to the bus stop. At the least, such barriers can cause distress to the disabled person involved, and at worst they can lead to journeys not being made.

Research for the Disabled Persons Transport Advisory Committee in the UK (DPTAC 2002) showed that 52 percent of disabled people are frustrated that they cannot make spontaneous journeys, and that this percentage rises to 82 percent among wheelchair users. The same research also indicated that 23 percent of disabled people encountered problems traveling to visit friends and relatives, and 23 percent encountered problems traveling to work-two types of journey that are likely to be "well-trodden" and where problems might, therefore, be expected to have been ironed out. Access requires ongoing management, however, and the nature of the public realm and transport services can change without warning, leaving people uncertain whether their journey will "work." When disabled and older people are concerned that their journey may not be possible because of barriers en route, fear of failure can shrink their journey horizons and seriously impact their quality of life (Employers' Forum on Disability 2008).

\subsection{The private car and the "blue badge"}

Within the UK, the number of blue badge holders is increasing (Wixey et al. 2006). There is also increasing demand (albeit currently strongly resisted) to widen the eligibility criteria for the badge (e.g. House of Commons Hansard 2007). Lack of attention to the journey chain reinforces disabled and older people's need to use cars-whether as drivers or as passengers-and the consequent use of blue badges.

The high rate of blue badge use, in turn, affects planners' ability to set goals in the areas of public health, environmental sustainability, and land use. For instance, housing projects that propose to limit car use through parking rationing nevertheless have to make provision for holders of the European "blue badge" (e.g. Camden Council 2007). In addition, the London 2012 Olympic and Paralympic Games, which is intended to be a car-free event, makes an exception for blue badge spaces for those who are unable to access the Games other than by car (Olympic Delivery Authority 2007). The number of blue badge spaces that will be provided has now reached "more than 550" (Disability Now 2007).

\subsection{Door-to-door provision}

There will always be some disabled and older people who are unable to reach their nearest public transport access point, and some people who will only be able to do so intermittently (e.g. when the weather is fair). Here the concept of "xtransit" (www.xtransit.org)-comprising a variety of urban transportation options that fall outside of traditional public transport-comes into its own. For many disabled and older people, door-to-door provision (whether through Diala-Ride, TaxiCard, or other forms of community transport in the UK) is vital to getting out and about; however, such services are often of poor quality and not readily available (Lansman 
2004; London Assembly Transport Committee 2008). In addition, there is no reason why such door-to-door, or door-to-transit-point, provision should not be available to anyone who needs it (at a price), thus taking provision out of the "special" segregated arena and improving the service.

\section{The appraisal process}

\subsection{Locating access for disabled people within appraisals}

A multiple-case study of the economic appraisal of three tram systems in the UK (Maynard 2007a) determined that a lack of attention to the benefits of features that address disabled people's needs during the economic appraisal process for transport projects created a barrier to the use of mainstream transport by disabled people. The UK framework addresses five objectives: Safety, Economy, Accessibility, Integration and Environment (UK Department for Transport 2006).

The concept of accessibility is an important one in considering issues of transport, land use, and disability. In transport planning, the term "accessibility" is often taken to mean the ease of reaching key services_-including food shops, schools, and hospitals-by public transport. It is generally assumed that distance is the key factor in determining accessibility. ${ }^{1}$ In relation to disability issues, the term "accessibility" usually means ease of access by disabled people to any service or facility, generally limited to the service or facility itself and perhaps the immediate surrounding area, but rarely the wider public realm or available transport services (e.g. Lacey 2004).

Because the term "accessibility" is used differently in different contexts, it is difficult to locate access for older and disabled people in the appraisal process. Disabled access could, indeed, sit happily within Accessibility, as it touches on both ease of access to key services and on how easily disabled people can use the system. But it can equally well sit within Integration, as being concerned with the fulfillment of "other government policies" such as Welfare to Work. Or it could sit within both-and, in some appraisals, it does just that. But as there is currently no clear guidance on how to incorporate disabled access, it often ends up at best as an anodyne statement about bringing benefits to disabled people - and at worst, is omitted entirely.

This research found that the Economy element of the appraisal generally took precedence over the other elements, largely because the prevailing government guidance (UK Department for Transport, 2005) establish a benefit:cost ratio below which a project will not go ahead. Costs of disabled access were found to be included in appraisals (often implicitly) whereas there was no accepted way to incorporate a monetary value for the benefits of accessible transport. In the example of Nottingham Express Transit, the UK Department for Transport rules in force at the time precluded the use of a proxy measure that could have provided a monetary value. As a consequence of the imbalance between costs and benefits, access is sometimes stripped out of a project; one of the tram projects considered did not provide an accessible link to the railway station on cost grounds.

This constitutes a barrier in organizational practice (in social model terms) to the inclusion of disabled people in UK mainstream transport provision. In consequence, it will always be an

\footnotetext{
${ }^{1}$ See Halden et al. (2005) for an exploration of the different uses of the term "accessibility" in the transport context.
} 
"uphill" push to ensure that disabled people's needs are addressed at the design and construction stages, since the costs apparently outweigh the benefits.

\subsection{Monetizing the benefits of disabled access}

Many advocates for greater access for disabled people have long held the view that making the environment more accessible for disabled people benefits non-disabled members of society (e.g. Hultgren 1995). While this view has previously been supported by qualitative evidence, quantitative support has been lacking-a situation that compounds the difficulty of including accessibility for the disabled, as outlined above. Fowkes et al. (1994) explored whether making transport accessible for disabled people would effectively pay for itself by reducing expenditures for services such as domiciliary visits by health professionals. However, the intrinsic value of accessible public transport, including its value to nondisabled people, has not previously been addressed.

In order to begin to address this lack, Maynard (2007b,c) undertook a stated-preference experiment using discrete choice modeling to determine whether there is economic value in methods of access that wheelchair users and people with walking difficulties can use to move between platforms at railway stations. The research took place at two venues in North-West London, near Harrow. The sample consisted of 411 people, recruited on the street. Quotas for age, sex, and rail use were used to ensure a broad range and to ensure that the research was able to capture people who might not be able to travel by rail because of barriers in the rail environment.

Respondents were offered a choice between two different options, each with a journey time, a journey cost, and a platform-to-platform access method. The methods offered were: stairs (the baseline for comparison), ramp only, ramp with stairs, and lift with stairs. Journey time was included in order to derive a value of time. This was compared with the UK Department for Transport current values of time (UK Department for Transport 2006) and provided external validation of the results. Of the platform-to-platform access methods, ramp with stairs and lift with stairs had economic value across the whole sample. For those with a clear need for these access methods, such as people who experience barriers in the physical environment and people with responsibility for children under five, the value of these access methods was higher, and for the former group there was also value in ramp-only access. Older people (over the age of 55) also had higher willingness-to-pay values for all three forms of access. Table 1 is an extract of the findings detailed in Maynard (2007b).

Table 1: Willingness-to-pay values for platform-to-platform access methods

\begin{tabular}{lrrrr}
\hline & $\begin{array}{r}\text { People who } \\
\text { experience } \\
\text { physical } \\
\text { barriers }\end{array}$ & $\begin{array}{r}\text { Older } \\
\text { people } \\
\text { (over 55) }\end{array}$ & $\begin{array}{r}\text { People with } \\
\text { responsibility for } \\
\text { children under 5 }\end{array}$ \\
\hline Rample & Not significant & & & $\begin{array}{r}\text { Not significant } \\
(p<0.05)\end{array}$ \\
Ramp with stairs & $£ 0.15$ & $£ 0.33$ & $£ 0.38$ & $(p<0.05)$ \\
Lift with stairs & $£ 0.48$ & $£ 0.93$ & $£ 0.98$ & $£ 0.32$ \\
\hline
\end{tabular}


This research tackled one small element of access provision. Research undertaken at the same time in Japan (Suzuki et al. 2007) looked at a wider range of disabled access features at rail stations (including toilets, escalators, and resting places on platforms) using contingent valuation and disaggregating the willingness-to-pay figure for the whole station by weighting the importance of each access feature. Results were split into willingness-to-pay values for disabled people, older people, and "able-bodied" people. A discussion of the merits of using contingent valuation for this kind of research is outside the scope of this paper, but the results demonstrate that travelers are willing to pay for all the access features considered in the study.

Both these studies demonstrate positive willingness-to-pay values for features of access for disabled people. The "whole sample" figures derived in the UK study were incorporated into two appraisals and had a positive effect on the benefit:cost ratios (Maynard 2007b). In addition, the study results enabled planners to distinguish between the different forms of access (ramps versus lifts) in the appraisal of benefits. It is likely that, in other transport environments and in relation to other access features in the rail environment, access features will have economic value. However, this is not captured in the appraisal process in the UK, and evidence of capturing the value for appraisals elsewhere has not been found. More research is needed, but the author believes this will demonstrate that a focus on the economic benefits of access provision for disabled and older people will provide a firm foundation for addressing access throughout the journey chain and ensuring a seamless journey. Only then will disabled and older people be encouraged to leave their cars and contribute to the achievement of social health, environmental, and land-use goals.

\section{Conclusion}

Attempts to get disabled and older people to leave their cars behind, whether for health, environmental or land-use reasons, will always falter unless efforts are also made to ensure that journeys by public transport (including walking and cycling) are seamlessly accessible.

This paper argues that the lack of attention paid to the economic benefits of providing access inhibits the capacity of the transport industry to provide the seamless journey. The lack of economic information leaves a gap in the appraisal process, and until this gap is filled, the pressure to provide access will only begin at design stage-whereas ideally attention should be paid to access from the very beginning of a process. The continuing exclusion of disabled and older people from mainstream transport provision will therefore remain a real risk. In consequence, disabled and older people will be forced to continue using cars, whether their own or others'. Only recently have the economic benefits of access provision in the transport environment been monetized and there is much work yet to be done on this. Public transport is unlikely ever to be wholly accessible for all disabled and older people, so a good door-to-door service-that could be used by everyone-will be required. In combination with accessible public transport, this could achieve in a healthier, "greener" and denser result.

\section{References}

Barnes, C. 1991. Disabled people in Britain and discrimination: A case for anti-discrimination legislation. London: Hurst \& Co. 
Camden Council. 2007. Camden council: Car free housing. URL http://www.camden.gov. $\mathrm{uk} / \mathrm{ccm} / \mathrm{content} / \mathrm{transport-and-streets/transport-strategies/car-free-housing.en.}$

Disability Now. 2007. Olympic parking raises blue badge questions. Scope.

Disability Rights Commission. 2004. Roads versus trains. URL http://83.137.212.42/ sitearchive/DRC/the_law/legal_commentary/roads_versus_trains.html.

DPTAC. 2002. Attitudes of disabled people to public transport. Reserach study, Disabled Persons Transport Advisory Committee. URL http://www.dptac.gov.uk/research/apt/index. htm.

Employers' Forum on Disability. 2008. Disability and public transport. URL http://www. realising-potential.org/case-studies/industry/disability-and-public-transport.html.

Fowkes, A., P. Oxley, and B. Heiser. 1994. Cross-sector benefits of accessible public transport. Cranfield, UK: Cranfield University Press.

Halden, D., P. Jones, and S. Wixey. 2005. Accessibility analysis literature review. Working paper, University of Westminster Transport Studies Group. URL http://home.wmin.ac. uk/transport/download/SAMP_WP3_Accessibility_Modelling.pdf.

House of Commons Hansard. 2007. Blue badge scheme. Written answers for 24 July 2007. URL http://www.publications.parliament.uk/pa/cm200607/cmhansrd/cm070724/text/ 70724w0002.htm.

Hultgren, K. 1995. Necessary to some and favourable to most others. SJ, Swedish State Railways Passenger Division, Tierps Tryckeri AB.

Imrie, R. 1996. Ableist geographies, disablist spaces: towards a reconstruction of Golledge's "Geography and the disabled". Transactions of the Institute of British Geographers, 21(2):397-403.

Kitchin, R. 1998. "out of place," "knowing one's place": Space, power and the exclusion of disabled people. Disability and Society, 13(3):343-356.

Lacey, A. 2004. Designing for accessibility. London: RIBA Enterprises.

Lansman, J. 2004. Door2door. Commission on Accessible Transport.

Litman, T. 2007. Measuring transportation: Traffic, mobility, and accessibility. Originally published in The ITE Journal, Vol. 73, No. 10, October 2003, pp. 28-32, http://www.vtpi. org/measure.pdf.

London Assembly Transport Committee. 2008. Door-to-door transport consultation. URL http://www.london.gov.uk/assembly/reports/transport/door_to\%_door.pdf.

Maynard, A. 2007a. The economic appraisal of tranpsort projects: The incorporation of disabled access. Doctor of business administration, Cranfield University School of Management. URL http://hdl.handle.net/1826/2046.

Maynard, A. 2007b. Monetising the benefits of disabled access in transport appraisal. In TRANSED 2007. Montreal. URL http://www.tc.gc.ca/pol/en/transed2007/pages/1218. htm.

Maynard, A. 2007c. The place of disabled access in economic appraisal in the UK. In TRANSED 2007. Montreal. URL http://www.tc.gc.ca/pol/en/transed2007/pages/1217. htm.

Miller, P., S. Parker, and S. Gillinson. 2004. Disablism: How to tackle the last prejudice. London: Demos.

Olympic Delivery Authority. 2007. Transport plan for the London 2012 Olympic and Paralympic Games. URL http://www.london2012.com/documents/oda-transport/ 
tp-first-edition/tp-ch-04-transport-strategy-for-the-games.pdf.

Passenger Focus. 2007. Mystery shop of the Assisted Passengers Reservation Service (APRS) offered to rail passengers with disabilities; summary of research conducted in London and the South East. INCOMPLETE REFERENCE: URL IS A GENERIC SEARCH PAGE.

Shakespeare, T. 1994. Cultural representation of disabled people: Dustbins for disavowal? Disability and Society, 9(3):283-299.

Suzuki, Y., K. Kodama, F. Takahachi, and Y. Nitta. 2007. Study on application of the socioeconomic evaluation technique to traffic barrier-free improvement/development projects. In TRANSED 2007. Montreal. URL http://www.tc.gc.ca/pol/en/transed2007/pages/1175. htm.

Transport for London. 2006. Disability equality scheme. CONFIRM CHANGED URL CORRECT DOCUMENT?, URL http://www.tfl.gov.uk/assets/downloads/corporate/ disability-equality-scheme-action-plan.pdf.

UK Department for Transport. 2006. Transport analysis guidance. URL http://www.webtag. org.uk/.

Wixey, S., A. Smith, and A. Maynard. 2006. Blue badge parking standards for off-street parking. London: Greater London Authority. 